\title{
Job Satisfaction among Elementary Teachers in Saudi Arabia
}

\author{
Hadi Alajmi
}

\begin{abstract}
The purpose of this study was to provide a systematic understanding of job satisfaction among elementary teachers in Saudi Arabia. A quantitative study was used to identify the demographic variables of teachers that have impact on their levels of job satisfaction. The study sampled 400 teachers in the elementary public school in Najran City, Saudi Arabia. A total of $81 \%$ of the 400 (324) participated in the survey; of the 342 taking the survey, 288 were valid and were analyzed for the purpose of the five null hypothesis of this study. The instruments used were (a) a demographic and background questions developed by the researcher, and (b) the Job Descriptive Index ([JDI]; Smith, Kendall, \& Hulin, 1969; Smith et al., 1987), which was translated into Arabic and validated by Maghrabi (1990). The dependent variables of the study were the six subscales of the JDI: present work, present payment, opportunities for promotion, supervision, co-workers, and job in general. The independent variables of the study were six demographic variables including years of experience, gender, level of education, marital status, and family size. A multivariate analysis of variance (MANOVA) test was applied to see if significant differences existed between teachers in each six subscales of job satisfaction based on the independent variable being examined for each null hypothesis. The major findings of the study were (a) a significant difference existed between teachers based on years of experience in present work and present pay; (b) a significant difference existed between teachers based on gender in present work, co-workers, and job in general subscales as female teachers were more satisfied than male teachers; (c) a significant difference did not exist between teachers based on level of education; (d) a significant difference did not exist between teachers based on marital status; and (e) a significant difference did not exist between teachers based on family size. Several recommendations to help improve job satisfaction of teachers were suggested.
\end{abstract}

Keywords - Job Satisfaction, Teachers' Job Satisfaction, Motivations, and Teachers in Saudi Arabia.

\section{INTRODUCTION}

It is in the best interest of any organization to value the job satisfaction of its employees because the morale of employees and the quality of their work will be increased when employees are satisfied (Bozeman \& Gaughan, 2011). According to Holdaway (1978), satisfied employees are more creative in their jobs. Many businesses conduct annual surveys to analyze employees' job satisfaction because of the recognition that job satisfaction can influence the overall organization function

S. B. Author was with Rice University, Houston, TX 77005 USA. He is now with the Department of Physics, Colorado State University, Fort Collins, CO 80523 USA
(Spector, 1997). Job satisfaction was found in several studies to positively increase productivity, increase commitment to the organization, and create better work environments (Judge, Thoreson, Bono, \& Patton, 2001). The increase of the level of job satisfaction for employees' results in the reduction of absenteeism and work related stress (Martin, 2006; Yousef, 2002).

\section{LITERATURE REVIEW}

\section{A. Theories of job satisfaction}

Contributions to the congress are welcome from throughout the world. A broad examination of the research on satisfaction showed that researchers have linked job satisfaction to motivation theories. Most of the literature on job satisfaction was built on the work of Maslow (1954) and Herzberg, Mausner, and Synderman (1959).

Maslow's need hierarchy model

Maslow developed the need hierarchy model in 1954. Regarding Maslow's model, Miskel (1982) reported,

Maslow's theory of an internal hierarchy proposes five levels of needs. Physiological needs are the basic biological functions of the human organism. Safety and security needs, the second level, relate to a desire for a peaceful, smoothly run, stable society. Belonging, love, and social needs comprise the third level. The fourth level, esteem needs, contains the desire for high regard by others. Achievement, competence, status, and recognition satisfy this need level. Finally, self-actualization is the highest level. (p. 70).

According to Maslow's theory, each of these five levels is the foundation for the next level and must be satisfied before moving to the upper levels. For instance, safety and security needs emerge only after physiological needs have been satisfied and so forth (Organ \& Bateman, 1986). Two implications are inherent in Maslow's theory. First, it is hard for organizations to identify the level of needs for all its employees so decisions can be made to satisfy those needs. Second, organizations must focus on satisfying lower-level needs so employees can be motivated by self-esteem and self-actualization needs (Howel \& Dipboye, 1986). Since Maslow's theory concerns human needs, it can be applied to teachers and their needs. Boeree (2006) explained the relationship among human needs graphically, which is represented in Figure 1. 


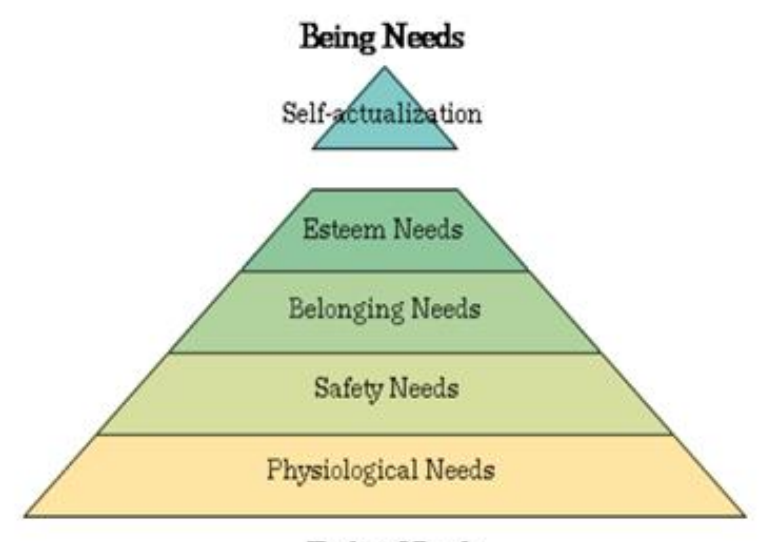

DeficitNeeds

Fig 1. Human needs. (Boeree, 2006).

When people satisfy a need, it does not influence behavior or work as motivators. However, unsatisfied needs can negatively influence the behavior. Human needs are arranged hierarchically from the lowest needs, such as the physiological need followed by the safety need, and so on to the highest need, which is the self-actualization need. The individual cannot move from the lower level to the level above until the lower level is at least minimally satisfied (Szilagy \& Wallace, 1990). Hall and Lindsey (1957) claimed, "When the needs that have the greatest potency and priority are satisfied, the next needs in the hierarchy emerge and press for satisfaction. When those needs are satisfied, another step up the ladder of motives is taken (p. 326)." According to Maslow (1954), the best employees in any organization are the self-actualized employees. This suggests that organizations should fulfill the highest level of needs possible for its employees. Maslow's theory can be applied to teachers and their needs since it concerns human needs.

Herzberg motivation-hygiene theory: Herzberg and his colleagues (1959) proposed a study similar to Maslow's need hierarchy in 1954. Herzberg introduced the motivation-hygiene theory, also named dual-factor theory and the two-factor theory. The theory focuses on factors causing satisfaction or dissatisfaction in the workplace rather than the human needs (Herzberg, 1976). Herzberg et al. (1959) conducted a study in which they interviewed 203 engineers and accountants. They asked every interviewee to describe an event he or she experienced at work. From the findings they were able to indicate two distinct groups of factors: the motivator's factors and the hygiene factors. Hygiene factors were defined by Costello and Welch (2014) as "the factors that cause dissatisfaction with work and are usually associated with supervision practices, policies and administration, and interpersonal relationships (p. 17)." Herzberg's theory assumed that employees are motivated by work itself. So when they complete their tasks, or meet goals of any assigned tasks, they satisfy their need and increase their motivation (Costello \& Welch, 2014).

\section{MethodOLOGY}

The main purpose of this study was to measure teachers' job satisfaction in elementary schools in Saudi Arabia as defined by a job satisfaction questionnaire. The study examined some variables that could influence teachers' levels of job satisfaction. Each participant's job satisfaction subscale score was the dependent variable, and the independent variables within this study were years of experience, gender, level of education, marital status, and family size. Information on dependent and independent variables was collected using the job satisfaction questionnaire. The data defined the impact of the independent variables on job satisfaction subscale scores, the dependent variable.

\section{Research Question Analysis and Null Hypotheses}

Research Question 1 was addressed through descriptive statistics.

Research Question 2: H01. Based on the participants' years of experience, there is no significant difference on the six JDI subscale scores of job satisfaction.

Research Question 3: H02. Based on the participants' gender, there is no significant difference on the six JDI subscale scores of job satisfaction.

Research Question 4: H03. Based on the participants' level of education, there is no significant difference on the six JDI subscale scores of job satisfaction.

Research Question 5: H04. Based on the participants' marital status, there is no significant difference on the six JDI subscale scores of job satisfaction.

Research Question 6: H05. Based on the participants' family size, there is no significant difference on the six JDI subscale scores of job satisfaction.

This was a quantitative study since we are measuring the phenomena of job satisfaction and collecting and analyzing numerical data. A questionnaire was sent to gather data needed to answer the research questions and to test the hypothesis of this study. The questionnaire contained two sections.

1. Demographic and background information included questions such as gender, age, years of experience, level of education, marital status, and family size. These items on the demographic data were used to determine what group each participant belongs to for each of the null hypotheses.

2. The Job Descriptive Index (JDI) collected data on job satisfaction about elementary teachers using JDI. The JDI used in this study is the most widely used instrument to measure the level of an employee's job satisfaction (Spector, 1997). JDI is constructed to measure six subscales of job satisfaction (a) the work itself, (b) pay, (c) promotion, (d) co-workers, (e) supervision, and (f) job in general.

The validity and reliability of any instrument is important in order to have appropriate measurement and for inferential judgment. For that reason, validity of the JDI took place from the beginning of its development (Balzer \& Smith, 1990). P. Smith et al. (1969) used many tests to test the validity of the JDI and found consistent validity. Schriesheim and Kinicki (1981) referred to JDI as "a high quality measuring instrument which has probably earned its place as the most commonly used measure of satisfaction" (p. 2). Vroom (1964) named the JDI 
"without doubt the most carefully constructed measure of job satisfaction in existence today" (p. 100).

The target population of this study was elementary schools teachers in Najran City, Saudi Arabia. The teachers of the sample were selected from public elementary schools in Najran City, Saudi Arabia. The education system in Saudi Arabia is different because male and female students are segregated throughout public education (Grades 1-12) and each gender is taught by the same gender. The elementary schools consist of six years: three years of middle school and three years high school. Male teachers and female teachers of elementary schools in the city of Najran were surveyed within this study. The teachers were given a survey to determine demographic information including gender, educational degree, experience, marital status, and family size. It determined the levels of satisfaction for each of the six subscales.

There are 334 elementary schools in Najran City, 163 schools for boys and 171 schools for girls (Najran Department of Education, 2016). I wrote the list of these schools alphabetically and randomly chose every fifth school on the list with a total of 20 elementary schools for each gender.

I retrieved the email addresses for teachers who work at those 20 schools from the Department of Education in Najran City. I randomly chose 10 teachers' email addresses from the list of each of the 40 schools. I emailed 400 teachers' a questionnaire containing a cover letter stating the purpose of the study, questions for collecting the demographic information, and the JDI.

\section{Data ANALYSIS}

The first part of the survey was designed to gather demographic information about the respondents. The demographic information detailed characteristics of the respondents. Demographic information collected included years of experience, gender, level of education, marital status, and family size. Respondents were asked to identify their gender. Out of the 288 total participants, 124 were male and 164 were female. Women made up $56.94 \%$ of the pool, and men made up $43.06 \%$ of the pool. Respondents were asked to provide their highest level of education attained. Of the 288 elementary teachers who responded to the survey, 242 teachers (84\%) had earned a bachelor's degree, while 37 teachers $(12.8 \%)$ had earned a master's degree. Only nine teachers (3.2\%) had earned a doctorate degree. Respondents were asked to provide their marital status. Of the 288 teachers who responded, 35 teachers $(12.2 \%)$ were single. The majority of teachers, 241 teachers $(83.7 \%)$, were married. Eight teachers (2.8\%) were divorced, and four teachers $(1.4 \%)$ were widowed. Respondents were asked to provide their years of experience in the teaching profession. Regarding their years of experience, 28 teachers $(9.7 \%)$ had 2 years of experience or less, 44 teachers $(15.3 \%)$ had more than 2 years and up to 5 years of experience, 78 teachers $(27.1 \%$ ) had more than 5 years and up to 10 years of experience, 39 teachers $(13.5 \%)$ had more than 10 years and up to 15 years of experience, 44 teachers $(15.30 \%)$ had more than
15 years and up to 20 years of experience. The remaining 55 teachers $(19.1 \%)$ had more than 20 years of experience. Respondents were asked to provide information regarding their family size. Of the 288 respondents who responded, 73 teachers (25.3\%) had no children, 69 teachers (24\%) had either 1 or 2 children, 85 teachers $(29.5 \%)$ had 3 or 4 children, 43 teachers $(14.9 \%)$ had 5 or 6 children, and 18 teachers $(6.3 \%)$ had more than 6 children.

\section{Hypothesis 1}

Hypothesis 1 aimed to see if a significant difference existed between participants in each subscale (present work, payment, promotional opportunities, supervision, co-workers, and job in general) of the JDI based on their years of experience. This null was examined using a multivariate analysis of variance (MANOVA).

The means of the six subscale scores were examined to determine whether there was a significant statistical difference between the six subscales based on their years of experience. The MANOVA determined a significant difference through the use of the Pillai's trace test, $F(30,1,405)=1.755, p<.001$. In order to determine which of the groups caused this significant difference, separate univariate tests were completed.

With a significant MANOVA result, a one-way ANOVA test for each of the six areas of the JDI was conducted to determine whether any of the groups were significantly different from one another based on years of experience.

The two areas of the JDI that demonstrated significant difference based on years of experience were present work $(\mathrm{p}=$ $.001)$ and present pay $(\mathrm{p}=.009)$. The Tukey HSD post hoc test indicated that teachers with more than 20 years experience had significantly higher satisfaction levels in present work than teachers with 5 years to 10 years experience group $(\mathrm{p}=.006)$. Additionally, the teachers with more than 20 years experience had significantly higher levels of satisfaction in their present work than both the $11-15$ years $(p=.007)$ and $16-20$ years groups $(\mathrm{p}=.027)$. All other comparisons within satisfaction of present work were not significant.

With regards to the satisfaction respondents had with pay, the group with 20 years or more of experience demonstrated significantly higher levels of satisfaction than the 2-5 year group $(\mathrm{p}=.012)$. The more than 20 years of experience group also was significantly higher than the $5-10$ group $(p=.018)$. All other comparisons within satisfaction of present pay were not significant. Finally, the four other areas of satisfaction on the JDI did not demonstrate any significant differences based on the years of experience. The overall null regarding significant differences on any of the six areas of JDI based on years of experience was rejected.

\section{Hypothesis 2}

Hypothesis 2 aimed to see if there was a significant difference between participants in each subscale of the JDI based on gender. This null was examined using a MANOVA. With a significant MANOVA result, a follow-up univariate test for each of the six areas of the JDI was conducted to determine whether there was significant difference between females and 
males. An f-test revealed that there was a significant difference between teachers based on gender in present work (.000), co-workers (.000), and job in general (.004) subscales. Females scored statistically significantly higher than their male counterparts in all three areas of satisfaction. According to the results of the analysis, in the present work subscale, male teachers (30.54) were less satisfied than female teachers (33.84). Moreover, in the co-workers subscale, male teachers (27.21) were less satisfied than female teachers (33.32). Nevertheless, in the job in general subscale, male teachers (38.19) were less satisfied than female teachers (42.71). The other three areas of satisfaction the JDI measures did not demonstrate any significant differences. The overall null regarding significant difference on any of the six areas of JDI based on gender has been rejected.

\section{Hypothesis 3-5}

The results of the MANOVA test indicated that the computed F-ratio for the participants in each subscale of the JDI and each one of the independent variables were not significant at .05 level in any of the six subscales of the JDI. Hypotheses 3-5 therefore were retained.

In response to the first research question, addressing differences between teachers job satisfaction based on their years of experience, present work and present pay subscales were found to be significant factor. Teachers with more than 20 years experience scored significantly higher than teachers with less experience in the present work and pay subscales. In response to the second research question, addressing differences between teachers job satisfaction based on their gender, present work, co-workers and job in general subscales were found to be significant factor. Female teachers scored significantly higher than male teachers in all three subscales present work, co-workers and job in general. In response to the third, fourth, and fifth research questions, addressing differences between job satisfaction of teachers based on their level of education, marital status, and family size, there were no significance differences on all six subscales.

Several implications and recommendations for future research resulted from this study. Based on the findings from this study, the Ministry of Education in Saudi Arabia should begin taking an in-depth look into teacher satisfaction. A start to increasing satisfaction for teachers in elementary schools in Saudi Arabia may begin by decreasing teaching loads, giving more autonomy to teachers, increasing teachers' salary, allowing more frequent promotions for teachers, improving communication channels with supervisors, and encouraging collaboration. Future research recommendations include replicating this study for middle schools, high schools, and private schools. A similar study should be conducted in other Saudi Arabian cities. This study could also be replicated for other school personnel other than teachers.

\section{REFERENCES}

[1] Bozeman, B., \& Gaughan, M. (2011). Job satisfaction among university faculty: Individual, work, and institutional determinants. The Journal of Higher Education, 82(2), 154-186.

https://doi.org/10.1353/jhe.2011.0011

[2] Holdaway, E., (1978). Faces and overall satisfaction of teachers. Educational Administration Quarterly, 14(1), 30-47.

https://doi.org/10.1177/0013161X7801400106

[3] Spector, P. E. (1997). Job satisfaction: Application, assessment, cause and consequences.

Thousand Oaks, CA: Sage.

[4] Judge, T. A., Thoreson, C. J., Bono, J. E., \& Patton, G. K. (2001). The job satisfaction-job performance relationship: A qualitative and quantitative review. Psychological

Bulletin, 127(3), 376-407.

https://doi.org/10.1037/0033-2909.127.3.376

[5] Martin, F. C. (2006). The relationship between leadership practices and job satisfaction: A survey analysis of National Aeronautics and Space Administration employees at the Langley Research Center (Doctoral dissertation). Capella University, Minneapolis, MN.

[6] Maslow, A. H. (1954). Motivation and personality. New York, NY: Harper \& Row.

https://doi.org/10.1111/j.1467-6494.1954.tb01136.x

[7] Herzberg, F., Mausner, F. B., \& Synderman, B. (1959). The motivation to work. New York, NY: Wiley.

[8] Miskel, C. C. (1982). Motivation in educational organizations. Educational Administration Quarterly, 18(3), 65-88.

https://doi.org/10.1177/0013161X82018003005

[9] Organ, D. W., \& Bateman, T. (1986). Organizational behavior ( $3^{\text {rd }}$ ed.). Englewood Cliffs, NJ: Prentice-Hall.

[10] Howel, W C. \& Dipboye, R. L. (1986). Essentials of industrial and organizational psychology. ( $3^{\text {rd }}$ ed.). Chicago, IL: Dorsey.

[11] Boeree, G. C. D. (2006). Personality theories. Retrieved from http://webspace.ship.edu/cgboer/perscontents.html

[12] Szilagy, A. D., \& Wallace M. J. Jr. (1990). Organization behavior and performance. $\left(5^{\text {th }}\right.$ ed.). Santa Monica, CA: HarperCollins.

[13] Hall, C. S., \& Lindsey, G. (1957). Theory of personality. New York, NY: Wiley.

[14] Costello, R., \& Welch, S. A. (2014). A qualitative analysis and student perceptions of effective online class communication using Herzberg' motivator-hygiene factors. Quarterly Review of Distance Education, $15(4), 15-24$ 